\title{
Exposure to Violence Across the Social Ecosystem and the Development of Aggression: A Test of Ecological Theory in the Israeli-Palestinian Conflict
}

\author{
Paul Boxer \\ Rutgers University and University of Michigan \\ Eric F. Dubow \\ Bowling Green State University and \\ University of Michigan \\ Khalil Shikaki \\ Palestinian Center for Policy and Survey Research
}

\author{
L. Rowell Huesmann \\ University of Michigan
}

Simha F. Landau and

Shira Dvir Gvirsman

Hebrew University of Jerusalem

Jeremy Ginges

New School for Social Research

\begin{abstract}
Bronfenbrenner's (1979) ecological model proposes that events in higher order social ecosystems should influence human development through their impact on events in lower order social ecosystems. This proposition was tested with respect to ecological violence and the development of children's aggression via analyses of 3 waves of data (1 wave yearly for 3 years) from 3 age cohorts (starting ages: 8, 11, and 14) representing three populations in the Middle East: Palestinians $(N=600)$, Israeli Jews $(N=451)$, and Israeli Arabs $(N=450)$. Results supported a hypothesized model in which ethnopolitical violence increases community, family, and school violence and children's aggression. Findings are discussed with respect to ecological and observational learning perspectives on the development of aggressive behavior.
\end{abstract}

Observing violence stimulates violence (Bandura, 1977; Huesmann, 1997; Huesmann \& Kirwil, 2007), and children's aggressive and violent behavior is particularly sensitive to the effects of violence in the social environment. Numerous field studies have demonstrated that despite aggression's dispositional substrates, children's observations of violence contribute to the development of habitual aggression (Eron, 1987). This is true for observations of violence in families (e.g., Boxer, Gullan, \& Mahoney, 2009; Dodge, Bates, \& Pettit, 1990), in neighborhoods (e.g., Gorman-Smith \& Tolan, 1998; Guerra, Huesmann, \& Spindler, 2003), in peer groups (e.g., Espelage, Holt, \& Henkel, 2003; Snyder et al., 2008), and in the mass media (e.g., Anderson, Gentile, \& Buckley, 2007; Huesmann, Moise-Titus, Podolski, \& Eron, 2003). For many children, observations and interactions in these environments socialize them away from early child-

This research was supported by a grant from the National Institute of Child Health and Human Development (Grant HD047814).

Correspondence concerning this article should be addressed to Paul Boxer, Department of Psychology, Rutgers University, Newark, NJ 07102. Electronic mail may be sent to pboxer@ psychology.rutgers.edu. hood predispositions toward aggression (Tremblay, 2000), but for others the observations and interactions enhance their risk for behaving aggressively later in life. These socialization experiences combine observational learning with conditioning to create potentially long-lasting habitual styles of behavior (Eron, 1987; Huesmann \& Kirwil, 2007).

Youths' aggressive behavior toward peers also has been shown to be related to exposure to ethnopolitical violence (Barber, 2008; Dubow et al., 2010; Kithakye, Morris, Terranova, \& Myers, 2010; Quota, Punamäki, \& El Sarraj, 2008). However, it is not very clear what the psychological processes are that lead youth to behave more aggressively against their peers after exposure to ethnopolitical violence committed by "outgroups." One possibility is that observation of ethnopolitical violence by youths directly affects their aggressiveness. Another possibility is that ethnopolitical violence in the youth's remote environment changes the violence level in more proximal environments (e.g., community,

(C) 2012 The Authors

Child Development (C) 2012 Society for Research in Child Development, Inc. All rights reserved. 0009-3920/2013/8401-0014

DOI: $10.1111 / j .1467-8624.2012 .01848 . x$ 
school, peers, and family), which in turn affect a youth's socialization. In line with the propositions of Bronfenbrenner's (1979) model of hierarchically nested ecosystems, we hypothesize that ethnopolitical violence affects children's aggression indirectly through its impact on violence in arenas of the social ecology that are theoretically more proximal to the individual child. Direct observational learning effects also might occur, but we propose that these indirect effects are an important element in stimulating increased aggressiveness in youth growing up in war-torn environments. In the present study, to test this theorizing, we examine the effects over time of ethnopolitical conflict violence on children's aggressive behavior. We use data collected in a longitudinal investigation of children's psychosocial development under conditions of persistent ethnopolitical violence and conflict in Israel and Palestine.

\section{Social Ecosystems Theory}

Bronfenbrenner (1979) has proposed that the social ecology of human development is composed of several nested layers of influences. At the center of his model is the individual, or self-system, influenced by personal, dispositional, and genetic factors. The first layer of social influence is termed the microsystem; the developing child transacts with a few different microsystems, including the family, the school, the peer group, and the neighborhood. Although Bronfenbrenner's (1979) initial conceptualization emphasized the relatively more unidirectional effects of social contexts on the developing child, it did acknowledge reciprocities between children and their environments in a manner similar to contemporary views on person-environment transactions (Sameroff, 2010). Bronfenbrenner's later work more explicitly addressed these reciprocities, with greater attention to the biological and predispositional characteristics children bring to bear on their social experiences (Bronfenbrenner, 2005). Indeed, there are numerous studies of interactions between children and the microsystems affecting them. For example, children affect and are affected by the dynamics of their parents' relationship (e.g., Boxer, Gullan, et al., 2009; Boxer, Huesmann, Bushman, O'Brien, \& Moceri, 2009; Cummings \& Davies, 1994), the biases and practices of their teachers (e.g., Boxer, Musher-Eizenman, Dubow, Heretick, \& Danner, 2006; Pianta, Steinberg, \& Rollins, 1995), and the norms and behaviors of their peers (e.g., Boxer, Guerra, Huesmann, \& Morales, 2005; Henry, Guerra, Huesmann,
Tolan, \& Van Acker, 2000). These actors and events external to the child are proximal ecological influences-that is, theoretically, social influences that are most proximal physically and psychologically to the child.

The next layer of the ecosystem as defined by Bronfenbrenner (1979) is the exosystem. The exosystem subsumes "one or more settings that do not involve the developing person as an active participant, but in which events occur that affect, or are affected by, what happens in the setting containing the developing person" (p. 25). For example, parents' economic transactions with the workplace or labor market that result in financial hardship strain their ability to parent effectively, in turn increasing the likelihood that their children will exhibit behavioral and emotional difficulties (Conger et al., 2002).

At the highest level of Bronfenbrenner's (1979) initial conceptual model is the macrosystem, which includes factors present in the larger culture such as beliefs and ideologies. The macrosystem is theorized to exert effects on development through its instantiation of "consistencies" (p. 26) that function as the backdrop to activities in lower level ecosystems. For example, with respect to the present study, the ongoing struggle between Jews and Arabs over land in the Middle East arguably dates back centuries. Undoubtedly, this history of conflict has led to distinct cultural values, ideologies, and identity that are shared by members of a given region tied to the conflict (see also Barber, 2008). In the present study, we hypothesize that, following a hierarchical model of ecosystem influence, the effects of ethnopolitical violence (experienced via the exosystem, but spurred by the macrosystem) on children's aggressive behavior will be partly indirect and accruing through the more proximal microsystem influences of intraethnic violence in families, schools, and communities.

\section{Violence Across the Social Ecosystem: Co-Occurrence and Causality}

The notion that violence in higher levels of the social ecology contributes to violence in lower levels of the social ecology is not new. For example, using crime rates and large-scale sociological data from Israel in the last third of the 20th century, Landau (Landau, 1988, 1997, 2003; Landau \& Pfeffermann, 1988) has obtained support for the basic tenets of Archer and Gartner's (1984) legitimization-habituation hypothesis. This hypothesis asserts that the sanctioning of killing interculturally during times of war normalizes and legitimizes 
killing and associated acts of violent crime intraculturally. Landau and Pfeffermann (1988) found that numbers of casualties emanating from violent ethnopolitical conflict in Israel predicted increases in homicide within the Israeli population over time. Via analyses of data collected in a nationally representative survey of the Palestinian population, Clark et al. (2010) observed significant cross-sectional relations between married women's reports of their husbands' exposure to ethnopolitical violence and engagement in acts of domestic violence. Cummings, Schermerhorn, et al. (2010) and Cummings, Merrilees, et al. (2010) demonstrated that historical experiences with political violence and ongoing experiences with sectarian violence were associated with current experiences of family conflict among families in Northern Ireland. This research implies critical links between events in the exosystem that theoretically impact microsystems.

Although an inference of causal directionality is supported by Landau and Pfeffermann's (1988) findings, and inferred in Clark et al.'s (2010) analysis, much of the available empirical literature on violence across social ecosystems only has demonstrated co-occurrence and not causality. Studies of children exposed to violence demonstrate that violence in different microsystems of the social ecology does appear to covary. For example, through a nationally representative survey of American children, Finkelhor, Turner, Ormrod, and Hamby (2009) documented significant associations among multiple forms of violence exposure, including victimization. Mrug, Loosier, and Windle (2008) reported modest but significant correlations among exposure to violence at home, in the community, and at school in a large sample of adolescents from the southern United States. In analyses of crosssectional data from research in Israel and Palestine, Dubow et al. (2010) and Landau et al. (2010) observed similarly sized relations among indicators of exposure to violence in families, neighborhoods, schools, and the broader ethnopolitical context. Still, studies documenting co-occurrence do not necessarily yield ready inferences of causal directionality.

\section{The Relation Between Exposure to Violence and Subsequent Aggression in Children}

Empirical studies based on social learning theory, particularly a cognitive-ecological model within this broader view, support a relation between exposure to violence and subsequent aggressive behavior (Bandura, 1977; Guerra \& Huesmann, 2004; Hues- mann, 1997; Huesmann \& Kirwil, 2007). For example, Huesmann and colleagues demonstrated that witnessing violence in the community, family, and media contributes to increases in habitual aggressive behavior over time (e.g., Eron, Huesmann, \& Zelli, 1991; Guerra et al., 2003; Huesmann et al., 2003). To study the impact of violence across multiple levels of the social ecosystem on the development of aggression, it is necessary to draw from a population likely to be experiencing violence in several systems simultaneously and in a reasonably persistent manner over time.

Our investigation focuses on children growing up in Israel and Palestine. Ethnopolitical violence and conflict is prevalent and ongoing in Israel and Palestine, where since the beginning of the second Intifada in September 2000 until the end of December 2008, at least 6,626 people have been killed as a consequence of ethnic-political violence ( $\mathrm{B}^{\prime}$ Tselem: Israeli Information Center for Human Rights in the Occupied Territories, 2009); over $16 \%$ of the fatalities have been children and adolescents. This region also is marked by moderate to high rates of other forms of violence, including domestic violence and youth violence (Krug, Dahlberg, Mercy, Zwi, \& Lozano, 2002). Thus, our sample permits us to examine the effects over time of violence witnessed via ongoing ethnopolitical conflict in the exosystem, sparking events occurring in the microsystem contexts. From a general developmental risk perspective (Rutter, 1979; Sameroff, 2000), children should be affected by violence present at all levels of their social ecology. Yet no known studies to date have examined this idea longitudinally and in line with the model of hierarchically nested ecosystems put forth initially by Bronfenbrenner (1979).

In this study we utilize data drawn from a cohortsequential longitudinal study of children's psychosocial development in the context of persistent ethnopolitical violence. As noted we sampled children from Israel and Palestine, and collected data from three cohorts, with starting ages of 8,11 , and 14 years. We test a model of how ethnopolitical violence contributes to increases in aggressive behavior over time. Specifically, we hypothesize that ethnopolitical violence will relate to increased aggression through its role in increasing other forms of violence-in communities, schools, and families (i.e., microsystemic). Furthermore, developmental theory and research suggest possible age differences in children's sensitivity to observational learning of aggression. For example, research emanating from cognitive-ecological theory has suggested late childhood as a critical period for the crystallization 
of cognitive beliefs that emerge through persistent exposure to aggressive behavior (Guerra \& Huesmann, 2004; Huesmann, 1998, 1997); this process might generalize to other self-beliefs and contextual experiences (e.g., achievement; Davis-Kean et al., 2008). Thus, we explore the possibility that the effects of violence exposure on aggression will be larger for our youngest age cohort.

\section{Method}

\section{Sampling Procedures}

Data are from all three waves of a longitudinal study of the effects of exposure to conflict and violence on behavioral mental health in three cohorts (ages: 8, 11, and 14 years at Wave 1) of youths growing up in Palestine $(N=600$ children) and in Israel $(N=901 ; 451$ Jewish and 450 Arab children).

Palestinian sample: Initial characteristics and attrition over time. The Palestinian sample at wave 1 is a representative sample of 600 children: 200 8-yearolds (101 girls, 99 boys), 20011 -year olds (100 girls, 100 boys) and 200 14-year olds (100 girls, 100 boys) and one of their parents ( $98 \%$ were mothers). On the basis of census maps of the West Bank and Gaza provided by the Palestinian Central Bureau of Statistics, residential areas were sampled proportionally to achieve a representative sample of the general population. First, Palestinian areas were divided into two areas: West Bank (64\% of the sample) and Gaza Strip (36\% of the sample), and counting areas were divided according to size. One hundred counting areas were selected randomly. In each counting area, a sample was selected whereby six children would be interviewed, three boys and three girls divided equally over the three ages under examination. Houses in each counting area were divided to allow random selection of six homes. In the first home, an interview could be conducted with any one of the six types of children needed; if there were more children who fit the description, one was selected using Kish Household Tables. In the second home, the age and gender type of child selected in the previous home would be excluded and so the choices would become five, rather than six, and so on. The total number of families that declined to be part of the sample was 61 ; the rejection rate was therefore 10\%. Staff from the Palestinian Center for Policy and Survey Research conducted the sampling and then the interviews.

Almost 100\% (599 of 600) of the parents reported their religion as Muslim and 99\% were married.
One third of the parents reported having at least a high school degree, and 47\% reported their incomes as below the Palestinian average, $33 \%$ reported it as average, and $20 \%$ reported it as above average. Parents reported that on average, there were 4.89 $(S D=1.86)$ children in the home. These statistics are representative of the general population of Palestinians based on the 2007 census (Palestinian Central Bureau of Statistics, 2008).

At Wave 2, 590 Palestinian children and their parents were again interviewed, for a resampling rate of 98\%; 572 Palestinian children and their parents were interviewed in Wave $3(95 \%)$. Wave 3 interviewing was briefly interrupted by the 2009 incursion of Israeli troops into Gaza, but the disruption in interviewing only lasted 2 weeks. $T$ tests of Wave 1 study variables revealed that there generally were no differences as a function of attrition between resampled and non-resampled children at Wave 2; parents of non-resampled children $(n=10)$ reported a higher income level $(p<.05)$ in Wave 1. Attrition in Wave 3 was associated $(p<.05)$ with lower child aggression in Wave 1.

Israeli sample: Initial characteristics and attrition over time. The Israeli sample included 901 children and their parents. The Arab group consisted of 450 children: one hundred and fifty 8-year-olds (66 girls, 84 boys), one hudrend and forty-nine 11-yearolds (69 girls, 80 boys) and one hundred and fiftyone 14-year-olds (79 girls, 72 boys) and one of their parents (68\% were mothers). The Jewish group consisted of 451 children: one hundred and fifty-one 8-year-olds (79 girls, 72 boys), one hundred and fifty 11-year-olds (73 girls, 77 boys), and one hundred and fifty 14-year-olds (94 girls, 56 boys), and one of their parents (87\% were mothers).

In comparison to the level of conflict and violence in Palestine, the level of conflict and violence is relatively low in the major population centers of Israel, so, we oversampled high-risk areas. Thus, of the Arab sample, $7 \%$ live in Jerusalem, $70 \%$ live in the north (close to the Lebanese border), and 23\% live in central Israel (low conflict area). Of the Jewish sample, $15 \%$ live in Jerusalem, $25 \%$ live in the north, 23\% live in the south (around the Gaza Strip), 24\% live in the occupied West Bank, and $14 \%$ live in central Israel.

Families in these designated areas were sampled randomly. They were approached in one of three ways: (a) recruitment by phone-random phone calls were made to households in the designated area, and the respondents were asked to participate in the project if they had children in one of the age cohorts, (b) recruitment by cluster sampling-within 
the designated area, we randomly selected neighborhoods and streets, and the interviewers then went door-to-door locating families with children fitting the sample criteria and asked them to take part in the project, and (c) nonprobability sampling-interviewees were allowed to recommend families who fit the sample criteria. Each family's census data were verified, and if their demographic characteristics indeed met the requirements, the family was included in the sample. Face-to-face interviews were scheduled for those who agreed to participate $(55 \%$ in the Jewish sample and $65 \%$ in the Arab sample). Staff from the Mahshov Survey Research Institute conducted the sampling and then the interviews.

Among the Israeli Jewish sample, $91 \%$ of the parents were married, over $80 \%$ had graduated from high school, and $42 \%$ reported their incomes as below the Israeli average, 28\% reported it as average, and 30\% reported it as above average. Parents reported that on average, there were 3.59 ( $S D=$ 1.83) children in the home.

Among the Israeli Arab sample, $92 \%$ of the parents were married, 55-60\% did not graduate from high school, and $43 \%$ reported their incomes as below the Israeli average, 37\% reported their income as average, and $21 \%$ reported it as above average. Parents reported that on average, there were $3.17(S D=1.39)$ children in the home.

At Wave 2, 305 Israeli Jewish children and their parents were again interviewed, for a resampling rate of $68 \%$, and at Wave 3, 282 Israeli Jewish children and their parents were interviewed $(63 \%)$. For Israeli Jews, $t$ tests of Time 1 study variables revealed that attrition in both Waves 2 and 3 was associated $(p<.05)$ with lower child aggression scores, less direct exposure to nonviolent political conflict, and lower parent education levels in Wave 1.

At Wave 2, 386 Israeli Arab children and their parents were reinterviewed (86\%), and at Wave 3, 385 Israeli Arab children and their parents were reinterviewed (86\%). For Israeli Arabs, attrition in Waves 2 and 3 was associated $(p<.05)$ with higher child aggression scores and greater exposure to all indicators of political violence at Wave 1 .

\section{Consent and Interview Procedures}

The research protocol was approved by the institutional review boards of the University of Michigan (Behavioral Sciences) and the Hebrew University of Jerusalem. In both Palestine and Israel, potential participants were told that the study concerned the effects of ethnic-political conflict on children and their families, assessments would take approximately $1 \mathrm{hr}$, and one parent and one child would be asked to participate. The voluntary and confidential nature of the study was emphasized. It should be noted that consent forms did not make explicit the fact that the study was being conducted simultaneously in Israel and Palestine. Written parent consent and child assent were obtained, which included a description of the study, the fact that participation was voluntary and could be ended at any time, and that participation would remain confidential. The family was compensated at the rate of $\$ 25$ for the 1-hr interview. The interviews of the parent and child were conducted in the families' homes separately and privately; interviewers read surveys to the respondents, who indicated answers that were then recorded by the interviewer. Interviewers worked in pairs; one interviewed the parent and the other interviewed the child.

The study was conducted in three yearly waves of assessment. Although the timing of waves in Palestine and that in Israel were similar, they did not overlap precisely. Wave 1 was conducted from May 2007 through September 2007 in Palestine, and from May 2007 through October 2007 in Israel. Wave 2 was conducted from May 2008 through September 2008 in Palestine, and from May 2008 through December 2008 in Israel. Wave 3 was conducted from May 2009 through August 2009 in Palestine, and from May 2009 through April 2010 in Israel. It should be noted that although we did not collect information concerning exposure to specific high-profile incidents of ethnic-political violence, we know that data collection did not occur in Palestine during the major 2008 incursion of Israeli troops into Gaza (Operation Cast Lead), which began operationally on December 27, 2008.

\section{Measures}

Demographic information. Parents responded to standard questions to assess demographic characteristics (e.g., age, gender). To assess indices of socioeconomic status, parent education was coded as follows: $1=$ illiterate to $10=$ doctorate or law degree. For income, parents were asked, "The average Palestinian (Israeli) income is XXX per month. Is your income: $1=$ below average to $5=$ way above average." The income question was worded in this manner rather than as a direct request for a family's income level because it is standard practice to word the income question in this manner in 
Palestine, according to the Palestinian Center for Population and Survey Research. Thus, the question was presented in this format in both regions.

Exposure to conflict and violence. To assess exposure to ethnic-political conflict and violence, parents of 8-year-olds reported on their children's exposure to political conflict and violence, whereas 11- and 14-year-old children provided self-reports of their exposure to political conflict and violence. The exposure to political conflict and violence scale includes 15 items adapted from Slone, Lobel, and Gilat (1999); as $=.86$ self-report and .87 for parent report. Respondents indicated the extent to which the child experienced the event in the past year along a 4 -point scale $(0=$ never to $3=$ many times $)$.

The 15 items comprised three domains of political conflict and violence events: loss of, or injury to, a friend or family member (five items, $\alpha=.65$ for parent report, $\alpha=.60$ for self-report; e.g., "Has a friend or acquaintance of yours been injured as a result of political or military violence?"'); experiencing security checks or threats (six items, $\alpha=.55$ for parent report, $\alpha=.50$ for self-report; e.g., "How often have you spent a prolonged period of time in a security shelter or under curfew?'”); and witnessing actual violence (four items, $\alpha=.60$ for parent report, $\alpha=.66$ for self-report; e.g., "How often have you seen right in front of you [members of your ethnic group] being held hostage, tortured, or abused by [members of the opposing ethnic group]?").

As noted, parents of 8-year-olds provided reports of their children's exposure to ethnic-political conflict and violence, but older children (11- and 14-year-olds) provided self-reports. We followed this strategy for two reasons. First, our Institutional Review Board had concerns about the 8-year-olds' emotional reactions to reporting on their exposure to this type of conflict and violence. Second, given the time constraints of the interviews with young children, having parents report on these items decreased the length of the interview for 8-year-olds. Based on analyses of data from a subsample of our youngest age cohort at Wave 3 (age: 10; $N=408$ ), we are confident that this measurement strategy was not problematic. In this sub-study, children's self-reports of exposure to ethnic-political conflict and violence were significantly related to parents' reports of the child's exposure $(r=.68)$.

Exposure to conflict and violence in other contexts also was assessed. The exposure to intraethnic community violence scale included four items taken from Attar, Guerra, and Tolan (1994) and Barber
(1999; $\alpha=.58)$. Although the original measure included more items, we deleted items that were not specific enough to distinguish between nonethnic "community or neighborhood violence" and ethnic-political conflict and violence (e.g., "How often have you had to hide someplace because of gunfire in your neighborhood?"). Thus, our items assessing "community violence" were not confounded with violence in the community that was clearly ethnic-political violence. Children responded to each item indicating the extent to which they experienced each event in the past year along a 4 -point scale $(0=$ never to $3=$ many times $)$. Sample items included: "How often has someone in your family been robbed or attacked by another [individual from the same ethnic group as yours]?" "How often have you seen or heard a violent argument between your neighbors?"

The exposure to School Conflict and Violence scale included three items taken from Attar et al. (1994; $\alpha=.78$ ). Children responded to each item indicating the extent to which they experienced each event in the past year along a 4-point scale $(0=$ never to $3=$ many times $)$. Sample items included: "How often have you seen violent physical fights between other kids at school or before or after school?" "How often have you seen a kid attacking another kid to take something from them at school or before or after school?"

For exposure to family conflict and violence, we used a single item adapted from Attar et al. (1994) to which children responded along a 4-point scale $(0=$ never to $3=$ many times in the past year $)$ : "How often have you seen or heard a violent argument between your adult relatives?"

Aggressive behavior. To assess severe physical aggression, children were administered the fouritem $(\alpha=.62)$ Severe Physical Aggression scale (Huesmann et al., 2003; Lefkowitz, Eron, Walder, \& Huesmann, 1977). Respondents indicated how often in the last year they had engaged in each behavior in the past year along a 4-point scale $(0=$ never to $3=5$ or more times). Sample items were: "How often have you punched or beaten someone?" and "How often have you choked someone?"

To assess general aggressive behavior, children responded to a modified, 10 -item $(\alpha=.80)$ version of the Peer Nomination of Aggression Inventory (Huesmann et al., 2003), based on the original peerrated index (Eron, Walder, \& Lefkowitz, 1971). Children provided ratings on a 4-point scale ranging from 0 (never) to 3 (almost always) on items measuring verbal aggression (e.g., "How often do you say mean things?"), physical aggression (e.g., 
"How often do you push or shove other kids?"), indirect aggression (e.g., "How often do you make up stories and lies to get others into trouble?"'), and acquisitive aggression (e.g., "How often do you take others' things without asking?"). In addition, parents reported on their children's aggressive behavior via the 20-item aggression subscale of the Child Behavior Checklist (Achenbach \& Edelbrock, $1983 ; \alpha=.89$ ). Parents rated the extent to which children displayed each behavior during the 6 months prior to assessment (e.g., "argues a lot," "threatens people," "gets in many fights") on a 3-point scale $(0=$ not true [as far as you know], $1=$ somewhat or sometimes true, 2 = very true or often true).

All measures described earlier were presented with no variation between waves of data collection. Measures were presented in appropriate native languages by region and ethnicity (i.e., Hebrew for Israeli Jews and Arabic for Palestinians and Israeli Arabs; Israeli Arabs were able to select Hebrew or Arabic). Original English measures were translated and back-translated for accuracy by native-speaking research teams at the two data collection sites. We also conducted two rounds of pilot testing on our survey battery with nine parent-child dyads (three from each age group) in each region. The pilot testing included asking participants to discuss any items or response formatting that caused confusion. Item content and response formatting of the measures were found to be understandable across age groups in the pilot testing.

\section{Results}

\section{Descriptive Analyses}

Table 1 shows descriptive information for all study variables across the three waves of data collection, including the proportion of youth who did not experience any violence across settings, along with information concerning mean differences by three key demographic indicators: ethnic group, gender, and age. As shown, Palestinian children experienced the greatest exposure to violence across all settings except "experiencing security checks or threats," which occurred most often for Israeli Jews. Palestinian children also showed the highest levels of aggressive behavior. Men experienced more exposure to violence and displayed higher levels of aggression than did women. Older cohorts tended to experience more violence and engage in more serious physical aggression than did the younger cohorts.
Table 2 shows the bivariate correlations for all the study variables, across the full sample. Despite variability in the strength of associations, generally aggressive behavior was moderately correlated with exposure to all types of violence across indicators, and exposure types were moderately intercorrelated. Most indicators were skewed significantly, so we log-transformed all variables prior to all subsequent analyses.

\section{Measurement Modeling}

Prior to examining structural models of variable relations, we first fit a measurement model to test our hypothesized latent variable composites. Specifically, we modeled exposure to microsystem violence as a latent variable indicated by exposure to family, school and community violence. We modeled exposure to inter-ethnic-political violence as a latent variable with three manifest indicators: experiencing loss or injury to family or friends, experiencing security threats and checks, and witnessing ethnopolitical violence in person. We also modeled aggression as a latent variable with three indicators: self-reports of mild aggression, self-reports of severe physical aggression, and parent reports of the child's general aggressive behavior. All Wave 1, 2 , and 3 indicators as described in the Method section were included, and the hypothesized data structure was tested as a multiple-group model across the three age cohorts. Models were computed using the Amos, version 7.0 (Amos Development Corporation, Spring House, PA), with missing data points estimated via the full information maximum likelihood (FIML) algorithm.

\section{Structural Modeling}

We examined three nested models in total by way of testing our primary hypothesized model. All models included covariance parameters among the two violence exposure constructs and aggression at Wave 1, and autoregressive paths linking the three latent constructs over time. First, we tested a three-group model with causal paths allowed to vary across the three age cohorts. Examination of the measurement models for aggression, exposure to ethnic-political violence, and exposure to microsystem violence had shown reasonable measurement invariance across age cohorts $\left(\chi^{2} / d f=\right.$ 2.670; root mean square error of approximation $[\mathrm{RMSEA}]=.033$, comparative fit index $[\mathrm{CFI}]=$ .916). Consequently, we tested a causal model with measurement weight parameters (i.e., relations of 
Table 1

Descriptive Statistics for Study Variables

\begin{tabular}{|c|c|c|c|c|c|c|c|c|c|c|c|c|}
\hline \multirow[b]{2}{*}{ Variable } & \multirow{2}{*}{$\begin{array}{l}\% \text { no } \\
\exp \end{array}$} & \multirow[b]{2}{*}{$M$} & \multirow[b]{2}{*}{$S D$} & \multirow[b]{2}{*}{ Range } & \multicolumn{3}{|c|}{ Ethn-regional group } & \multicolumn{2}{|c|}{ Sex } & \multicolumn{3}{|c|}{ Age } \\
\hline & & & & & $p$ & $\eta^{2}$ & Diff & $p$ & $\eta^{2}$ & $p$ & $\eta^{2}$ & Diff \\
\hline \multicolumn{13}{|c|}{ Exposure to pol conflict/violence $(0=$ never to $3=$ many times $)$} \\
\hline Loss/injury friend/family (T1) & 58.1 & .214 & .355 & $0-2.5$ & .000 & .084 & $\mathrm{P}>\mathrm{J}>\mathrm{A}$ & .000 & .013 & .077 & .003 & - \\
\hline Loss/injury friend/family (T2) & 64.8 & .166 & .308 & $0-2.6$ & .000 & .111 & $\mathrm{P}=\mathrm{J}>\mathrm{A}$ & .017 & .005 & .016 & .007 & $14>11$ \\
\hline $\begin{array}{l}\text { Experienced security checks } \\
\text { or threats (T1) }\end{array}$ & 26.9 & .474 & .468 & $0-2.8$ & .000 & .093 & $\mathrm{~J}>\mathrm{P}>\mathrm{A}$ & .001 & .007 & .000 & .033 & $14>11>8$ \\
\hline $\begin{array}{l}\text { Experienced security checks } \\
\text { or threats (T2) }\end{array}$ & 40.4 & .355 & .434 & $0-3$ & .000 & .224 & $\mathrm{~J}>\mathrm{P}>\mathrm{A}$ & .000 & .012 & .000 & .024 & $14=11>8$ \\
\hline Witness actual violence (T1) & 55.3 & .388 & .587 & $0-3$ & .000 & .230 & $\mathrm{P}>\mathrm{J}=\mathrm{A}$ & .000 & .024 & .000 & .039 & $14>11>8$ \\
\hline Witness actual violence (T2) & 60.3 & .307 & .512 & $0-3$ & .000 & .138 & $\mathrm{P}>\mathrm{J}>\mathrm{A}$ & .006 & .006 & .015 & .007 & $14>11=8$ \\
\hline \multicolumn{13}{|c|}{ Exposure to other violence $(0=$ never to $3=$ many times $)$} \\
\hline Community violence (T1) & 26.8 & .588 & .571 & $0-3$ & .000 & .140 & $\mathrm{P}>\mathrm{A}>\mathrm{J}$ & .004 & .006 & .000 & .025 & $14>11>8$ \\
\hline Community violence (T2) & 32.6 & .534 & .553 & $0-3$ & .000 & .082 & $\mathrm{P}>\mathrm{A}>\mathrm{J}$ & .023 & .004 & .000 & .026 & $14>11=8$ \\
\hline Family violence (T1) & 51.8 & .903 & 1.079 & $0-3$ & .000 & .172 & $\mathrm{P}>\mathrm{A}>\mathrm{J}$ & .936 & .000 & .008 & .007 & $14>8$ \\
\hline Family violence (T2) & 58.7 & .816 & 1.085 & $0-3$ & .000 & .141 & $\mathrm{P}>\mathrm{A}>\mathrm{J}$ & .373 & .001 & .020 & .006 & $14>11=8$ \\
\hline School violence (T1) & 6.4 & 2.021 & .902 & $0-3$ & .000 & .068 & $\mathrm{P}>\mathrm{A}=\mathrm{J}$ & .000 & .023 & .004 & .007 & $11>8$ \\
\hline School violence (T2) & 11.7 & 1.906 & 1.023 & $0-3$ & .000 & .180 & $\mathrm{P}>\mathrm{J}>\mathrm{A}$ & .000 & .022 & .964 & .000 & - \\
\hline \multicolumn{13}{|l|}{ Aggressive behavior in last year } \\
\hline Serious physical aggression (T1) & - & .160 & .135 & $0-.58$ & .000 & .106 & $\mathrm{P}>\mathrm{J}=\mathrm{A}$ & .000 & .065 & .000 & .023 & $11=14>8$ \\
\hline $\begin{array}{l}\text { Serious physical aggression } \\
(\mathrm{T} 3 ; 0=\text { never }, 3=\text { five or more } \\
\text { times })\end{array}$ & - & .133 & .142 & $0-.58$ & .000 & .301 & $\mathrm{P}>\mathrm{J}>\mathrm{A}$ & .000 & .045 & .323 & .002 & - \\
\hline General aggression-self rate (T1) & - & .467 & .455 & $0-3$ & .000 & .024 & $\mathrm{P}>\mathrm{J}=\mathrm{A}$ & .000 & .025 & .000 & .019 & $14=11>8$ \\
\hline $\begin{array}{l}\text { General aggression-self rate } \\
(\mathrm{T} 3 ; 0=\text { never, } 3=\text { almost } \\
\text { always })\end{array}$ & - & .314 & .399 & $0-2.2$ & .000 & .113 & $\mathrm{P}=\mathrm{J}>\mathrm{A}$ & .000 & .011 & .353 & .002 & $14>8$ \\
\hline General agg-parent CBC (T1) & - & .545 & .409 & $0-2$ & .000 & .168 & $\mathrm{P}>\mathrm{A}>\mathrm{J}$ & .000 & .026 & .111 & .003 & - \\
\hline $\begin{array}{l}\text { General agg-parent CBC } \\
\text { (T3; } 0=\text { not true, } 2=\text { very true) }\end{array}$ & - & .461 & .423 & $0-2$ & .000 & .332 & $\mathrm{P}>\mathrm{J}>\mathrm{A}$ & .000 & .013 & .012 & .007 & $8=11>14$ \\
\hline
\end{tabular}

Note. $P=$ exact $p$ value for significance test; $\eta^{2}=$ partial eta-squared value for effect; diff $=$ direction of observed significant differences; $\mathrm{P}=$ Palestinian; J = Israeli Jew; A = Israeli Arab; M = Male; F = Female; CBC = Child Behavior Checklist. All significant differences by child sex reflect higher scores for males.

indicators to latent constructs or metric invariance; Cheung \& Rensvold, 2002) constrained to be the same across the three age groups.

Model 1 is the reciprocal influence model in which political violence, microsystem violence, and aggression all reciprocally affect each other. It includes paths allowing Wave 1 aggression to predict Wave 2 microsystem and political violence exposure, and microsystem and political violence to cross-predict each other over time and to predict later aggression. In Model 2, we eliminated aggression as a cause of exposure to both political violence and microsystem violence. If aggression did not affect exposure (see Richards et al., 2004), it should not change the fit achieved with Model 1. Model 3 is the unidirectional influence model hypothesizing that political violence affects microsystem violence but that microsystem violence does not affect political violence. In this model we dropped the path linking Wave 1 microsystem violence exposure to Wave 2 political violence exposure. Also estimated was Model 4, which tested by way of comparison the counterfactual case to our theory, dropping the path from Wave 1 political violence exposure to Wave 2 microsystem violence exposure and returning the path from Wave 1 microsystem violence exposure to Wave 2 political violence exposure.

The parameters of each of these models were estimated, and the goodness of fit of each model was compared with the goodness of fit of the models nested within it. The goal of testing the nested models in this manner was to determine whether or not a model implied by Bronfenbrenner's (1979) theory could be fit to our data. In particular we questioned whether or not a model representing 
Table 2

Correlations among the Study Variables

\begin{tabular}{|c|c|c|c|c|c|c|c|c|c|c|c|c|c|c|c|c|c|c|}
\hline Variable & 1 & 2 & 3 & 4 & 5 & 6 & 7 & 8 & 9 & 10 & 11 & 12 & 13 & 14 & 15 & 16 & 17 & 18 \\
\hline 1 E-pv-loss 1 & - & & & & & & & & & & & & & & & & & \\
\hline 2 E-pv-loss 2 & $.35^{* *}$ & - & & & & & & & & & & & & & & & & \\
\hline 3 E-pv-st 1 & $.36^{* *}$ & $.20^{* *}$ & - & & & & & & & & & & & & & & & \\
\hline 4 E-pv-st 2 & $.14^{* *}$ & $.32^{* *}$ & $.42^{* *}$ & - & & & & & & & & & & & & & & \\
\hline 5 E-pv-wv 1 & $.40^{* *}$ & $.31^{* *}$ & $.32^{* *}$ & $.12^{* *}$ & - & & & & & & & & & & & & & \\
\hline 6 E-pw-wv 2 & $.27^{* *}$ & $.37^{* *}$ & $.20^{* *}$ & $.26^{* *}$ & $.44^{* *}$ & - & & & & & & & & & & & & \\
\hline 7 E-com 1 & $.19^{* *}$ & $.14^{* *}$ & $.14^{* *}$ & -.02 & $.36^{* *}$ & $.21^{* *}$ & - & & & & & & & & & & & \\
\hline 8 E-com 2 & $.17^{* *}$ & $.23^{* *}$ & $.12^{* *}$ & $.12^{* *}$ & $.29^{* *}$ & $.32^{* *}$ & $.42^{* *}$ & - & & & & & & & & & & \\
\hline 9 E-fam 1 & $.14^{* *}$ & $.11^{* *}$ & .03 & $-.09^{* *}$ & $.32^{* *}$ & $.22^{* *}$ & $.47^{* *}$ & $.28^{* *}$ & - & & & & & & & & & \\
\hline 10 E-fam 2 & $.17^{* *}$ & $.13^{* *}$ & $.06^{*}$ & $.06^{*}$ & $.25^{* *}$ & $.27^{* *}$ & $.29^{* *}$ & $.45^{* *}$ & $.34^{* *}$ & - & & & & & & & & \\
\hline 11 E-sch 1 & $.15^{* *}$ & $.12^{* *}$ & $.12^{* *}$ & $.06^{*}$ & $.25^{* *}$ & $.18^{* *}$ & $.40^{* *}$ & $.23^{* *}$ & $.32 * *$ & $.18^{* *}$ & - & & & & & & & \\
\hline 12 E-sch 2 & $.16^{* *}$ & $.21^{* *}$ & $.11^{* *}$ & $.15^{* *}$ & $.26^{* *}$ & $.29^{* *}$ & $.24^{* *}$ & $.43^{* *}$ & $.20^{* *}$ & $.38^{* *}$ & $.36^{* *}$ & - & & & & & & \\
\hline $13 \mathrm{SrPag} 1$ & $.18^{* *}$ & $.11^{* *}$ & $.15^{* *}$ & $.06^{*}$ & $.27^{* *}$ & $.15^{* *}$ & $.28^{* *}$ & $.14^{* *}$ & $.23^{* *}$ & $.21^{* *}$ & $.31^{* *}$ & $.20^{* *}$ & - & & & & & \\
\hline 14 SrPag 3 & $.20^{* *}$ & $.15^{* *}$ & $.10^{* *}$ & $.09^{* *}$ & $.25^{* *}$ & $.25^{* *}$ & $.10^{* *}$ & $.17^{* *}$ & $.11^{* *}$ & $.26^{* *}$ & $.20^{* *}$ & $.33^{* *}$ & $.42^{* *}$ & - & & & & \\
\hline 15 GAggS 1 & $.17^{* *}$ & $.10^{* *}$ & $.19^{* *}$ & $.07^{*}$ & $.23^{* *}$ & $.13^{* *}$ & $.27^{* *}$ & $.17^{* *}$ & $.23^{* *}$ & $.20^{* *}$ & $.23^{* *}$ & $.14^{* *}$ & $.64^{* *}$ & $.36^{* *}$ & - & & & \\
\hline 16 GAggS 3 & $.16^{* *}$ & .03 & $.18^{* *}$ & $.13^{* *}$ & $.16^{* *}$ & $.12^{* *}$ & $.05^{\dagger}$ & $.05^{\dagger}$ & .02 & $.16^{* *}$ & $.09 * *$ & $.14^{* *}$ & $.38^{* *}$ & $.57^{* *}$ & $.37^{* *}$ & - & & \\
\hline 17 GAggP 1 & $.19^{* *}$ & $.10^{* *}$ & $.08^{* *}$ & -.03 & $.24^{* *}$ & $.20^{* *}$ & $.25^{* *}$ & $.14^{* *}$ & $.25^{* *}$ & $.21^{* *}$ & $.24^{* *}$ & $.21^{* *}$ & $.31^{* *}$ & $.25^{* *}$ & $.25^{* *}$ & $.14^{* *}$ & - & \\
\hline 18 GAggP 3 & $.23^{* *}$ & $.17^{* *}$ & .03 & .03 & $.25^{* *}$ & $.25^{* *}$ & $.13^{* *}$ & $.18^{* *}$ & $.16^{* *}$ & $.28^{* *}$ & $.19^{* *}$ & $.31^{* *}$ & $.23^{* *}$ & $.47^{* *}$ & $.14^{* *}$ & $.35^{* *}$ & $.63^{* *}$ & - \\
\hline
\end{tabular}

Note. Numbers after variable names denote Wave 1 or 2 . E-pv-loss = exposure to political violence-loss; E-pv-st = exposure to political violence-security threats; E-pv-wv = exposure to political violence-witnessing violence; E-com = exposure to intraethnic community violence; E-fam = exposure to family violence; E-sch = exposure to school violence; SrPag = serious physical aggression; GAggS = general aggression self-report; GAggP = general aggression parent report.

${ }^{\dagger} p<.10 .{ }^{*} p<.05 .{ }^{* *} p<.01$.

the influence on the child of ethnopolitical violence in the child's exo- and macrosystems by its influence on the child's microsystem environment fit our data as well as models assuming that microsystem factors and the child's behavior could affect the exo- and macrosystems.

Model 1, the complete reciprocal influence model, yielded an adequate fit to the data $\left(\chi^{2}=\right.$ 997.85, $d f=363, p<.001, \chi^{2} / d f=2.749, \mathrm{CFI}=.910$, RMSEA $=.034$ [.032-.037]), as did Model 2, in which the influence of aggression on exposure to political or microsystem violence was removed $\left(\chi^{2}=998.972, d f=369, p<.001, \chi^{2} / d f=2.707, \mathrm{CFI}=\right.$ .911 , RMSEA $=.034$ [.031-.036]). Furthermore, Model 2 fit the data just as well as Model $1\left(\chi^{2}\right.$ difference $=1.122, d f=6, n s)$. Model 3, in which the influence of child's microsystem exposure to violence on exposure to political violence additionally was removed, also fit the data well $\left(\chi^{2}=1000.77\right.$, $d f=372, p<.001, \chi^{2} / d f=2.690$, CFI $=.911$, RMSEA $=.034[.031-.036])$, and was not significantly different from Model $2\left(\chi^{2}\right.$ difference $\left.=1.796, d f=3, n s\right)$. Model 4, the counterfactual case to Model 3 with microsystem violence influencing exposure to political violence but without political violence influencing exposure to microsystem violence, fit worse than did Model $3\left(\chi^{2}=1018.37, d f=372, p<.001\right.$, $\chi^{2} / d f=2.738, \quad$ CFI $=.909, \quad$ RMSEA $=.034 \quad[.032-$ .037]), and, in contrast to Model 3, fit significantly worse than did Model $2\left(\chi^{2}\right.$ difference $=19.401$, $d f=3, p<.001$ ).

Our conclusion is that the observed longitudinal relations can be explained adequately and best with Model 3-a model in which exposure to political violence influences microsystem violence and aggression, but neither microsystem violence nor aggression influences an individual's exposure to political violence. Model 3, with the final standardized parameter estimates for each age group, is shown in Figure 1. For all age cohorts exposure to political violence at Time 2 is strongly related to exposure at Time 1 and has a significant direct effect on aggressive behavior at Time 3. In addition, exposure to political violence at Time 1 significantly predicts changes in microsystem violence from Time 1 to Time 2. Microsystem violence at Time 2 in turn significantly predicts aggressive behavior at Time 3 for 8-year-olds with the effects decreasing with increasing age of the youth. Consequently, exposure to political violence only shows the hypothesized indirect effect on aggression mediated by microsystem violence for 8-year-olds (indirect effect $=.037$ [.001-.089], $p<.10)$. 


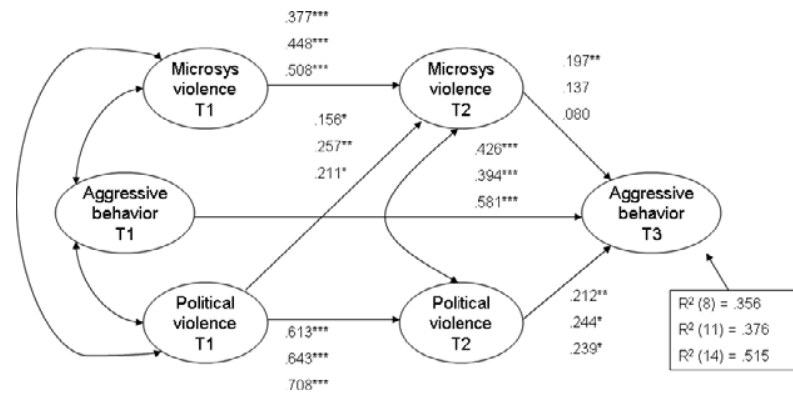

Figure 1. Final estimates for Model 3 shown separately by age (top row $=$ age 8 , middle row $=$ age 11 , bottom row $=$ age 14 ). Note. Model fit: $\chi^{2}=1000.77, d f=372, p<.001, \chi^{2} / d f=2.690$, $\mathrm{CFI}=.911, \mathrm{RMSEA}=.034(.031-.036)$.

${ }^{*} p<.05 .{ }^{* *} p<.01 .{ }^{* * *} p<.001$.

This model implies that over time, political violence leads directly to increased aggressive behavior as well as increased exposure to microsystem violence. In addition, for younger children, the effect of political violence on microsystem leads in turn to increased aggressive behavior. Neither the child's aggressive behavior nor microsystem violence to which the child is exposed influences exposure to political violence, nor does the child's aggression influence exposure to microsystem violence.

We next examined the extent to which we could constrain the specified path coefficients estimated for model across age groups, given that the measurement parameters were already constrained to be invariant. These analyses indicated that imposing additional constraints significantly worsened the overall fit of the model. We then added demographic control variables to the model by specifying them as exogenous predictors, allowing them to covary with the initial predictor set, and adding directional paths from the controls to Time 3 aggression. Demographic controls were child gender (coded as $1=$ male, $0=$ female), family income level, and parental educational level. In these analyses we are effectively constraining measurement weights to be the same across gender, which seems justified given preliminary analyses suggesting that our measurement model showed general metric invariance with respect to gender $\left(\chi^{2} / d f=3.583\right.$; RMSEA $=.042, \mathrm{CFI}=.913)$. Although not included as a control variable to preserve important variation in exposure, we also observed general metric invariance with respect to ethnic group $\left(\chi^{2} / d f=\right.$ 2.581; RMSEA $=.032$, CFI $=.898$ ).

The new model with demographic controls included, called Model 5, is shown in Figure 2. Although in this model, education significantly

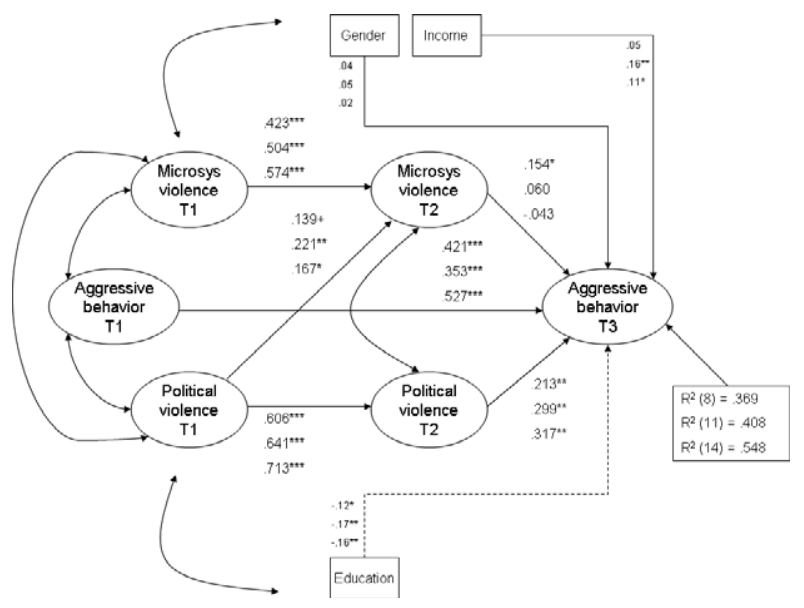

Figure 2. Final estimates for Model 5 shown separately by age. Note. For clarity, not all covariance paths between pairs of exogenous variables are shown; demographic controls were allowed to covary with principal predictors. Model fit: $\chi^{2}=1437.08, \quad d f=498, \quad p<.001, \quad \chi^{2} / d f=2.886, \quad$ CFI $=.881$, RMSEA $=.035(.033-.038)$.

${ }^{*} p<.05 .{ }^{* *} p<.01 .{ }^{* * *} p<.001$.

predicts aggression for all ages and income for the age 11 and 14 cohorts, the model fits significantly worse than did the same model without demographic controls (Model 3: $\chi^{2}=1437.08, d f=498$, $p<.001, \chi^{2} / d f=2.886$, CFI $=.881$, RMSEA $=.035$ [.033-.038]; $\chi^{2}$ diff $\left.=436.31, d f=126, p<.001\right)$. As with Model 3, attempts to add parameter constraints across age groups beyond the measurement weights worsened the fit.

\section{Discussion}

In this study, we examined the effects over time on aggressive behavior of exposure to violence across multiple social settings representing different levels of the hierarchically ordered social ecology as theorized by Bronfenbrenner (1979). Our analyses utilized multi-informant data obtained through a 3-year cohort-sequential study of children growing up in Israel $(N=901)$ and Palestine $(N=600)$. We hypothesized that the effects of exposure to persistent ethnopolitical violence on aggressive behavior would be partially indirect, through the effect of ethnopolitical violence on family, school, and community violence. In other words, we hypothesized that violence in the exosystem would impact child development through its role in increasing violence in microsystems. Following contemporary social-cognitive and social learning theory on the development of aggression (e.g., Huesmann, 1998; 
Huesmann \& Kirwil, 2007), we hypothesized further that these relations would be stronger in our youngest age cohort. We observed a pattern of effects consistent with Bronfenbrenner's theory, and obtained partial support for our hypotheses. The results of this investigation have significant implications for ecological theories of behavioral development, particularly as applied to high-risk social contexts in which children are exposed to violence and similar adversity across multiple settings. In addition, the results underscore the very real risks to children of exposure to violence that is sustained over time across multiple settings and extend earlier findings of negative impacts for political violence.

\section{Descriptive Findings}

Our data were collected from three different samples marked by ethnic and regional characteristics-Palestinian Arabs, Israeli Arabs, and Israeli Jews. The samples were fairly evenly divided by gender and across three age cohorts at Waves 1-8, 11, and 14. Although there was some modest variation in selected indicators, Palestinian children were at the greatest risk for exposure to violence across settings as well as at the highest level of aggressive behavior in comparison to the two other groups. Men were uniformly at greater risk than were women for all forms of exposure to violence as well as more aggressive. Mean-level differences in exposure and aggression by age were more variable, although generally our oldest cohort tended to experience more violence. The oldest cohort, however, was not uniformly more aggressive than were the younger cohorts.

Our observations of mean-level differences (or the lack thereof) in study indicators as a function of gender and age are consistent with current theory and typical results in cross-sectional as well as longitudinal studies of exposure to various forms of violence and of aggressive behavior development. Men are more aggressive than women, particularly when the measurement is weighted toward typically physical, direct forms of aggression (Huesmann et al., 2003; Huesmann, Dubow, \& Boxer, 2009; Kokko, Pulkkinen, Huesmann, Dubow, \& Boxer, 2009). With respect to gender differences in exposure, this finding certainly warrants further research especially in regard to the understudied phenomenon of ethnopolitical violence. It might be the case that, by virtue of elevated aggressiveness and concomitant tendencies toward association with aggressive peers (Espelage et al., 2003), men might select into situations as well as broader social networks or crowds that are connected to, or more knowledgeable of, acts of political conflict and violence. In terms of age differences, it has long been observed that aggressive behavior tends to increase from late childhood and into early adolescence, with little variation thereafter (Nansel et al., 2001; Tremblay, 2000).

Results showing differences in exposure and behavior linked to Middle Eastern ethnic group and region contribute new information to the literature. This is the first known study to present direct comparisons via the same measurement batteries among the three predominant ethnic groups involved in the Middle Eastern conflict; these comparisons highlight the importance of assessing the experiences of all parties to large scale ethnopolitical conflict. What our results suggest is that Palestinian children appear to be at the greatest risk of exposure to various forms of violence in their social ecology, as well as at the greatest risk for exhibiting various forms of aggressive behavior. It is difficult to address the potential meaning of this observation without becoming entangled in the political underpinnings of the ongoing conflict between Palestine and Israel. However, we can suggest that the validity of these ethnic group differences is bolstered by our decision not to inform participants that their responses could be compared across Palestinian and Israeli subgroups, thus mitigating political motives behind participants' accounts. It also should be emphasized here that the unique aspects of the conflict between Palestine and Israel-particularly its duration and known relation to elevated rates of domestic and youth violence-suggest that our results might not necessarily generalize to ethnic-political conflict in other regions of the world.

At the same time, the ethnic-regional differences in exposure to violence in our data set did present a challenge to hypothesis testing. When a known demographic factor (here, ethnicity) accounts for a significant and substantial amount of variance in some target outcome, its inclusion in statistical models can attenuate the impact of other variables that potentially of greater theoretical interest or practical relevance. For example, in a study of how violent media preferences relate to antisocial behavior in a large sample composed of juvenile delinquents and nondelinquent high school students, Boxer, Huesmann, et al. (2009) observed large differences in antisocial behavior as the result of - not surprisingly-delinquent status. By combining the two samples, and thereby maximizing the range 
and variability of the behavioral criterion scores, the authors were able to identify the significant effects of violent media preferences on behavior. This then permitted the conclusion that reducing exposure to violent media might have a salutary effect on antisocial responding. In the present case, we deliberately omitted ethnicity from our structural models (despite adequate metric invariance by ethnicity) because our theory is concerned primarily with age differences and the relations over time of exposure to political violence, microsystem violence, and aggressive behavior. We only could capture the variation in exposure that we needed to test our theory-driven hypotheses by combining all three subsamples of participants and setting aside the problematic confound of ethnicity with exposure.

\section{Effects of Violence Across the Social Ecosystem}

Multiple-group structural equation modeling analyses using age cohort as the grouping variable produced support for our hypothesized model of directional effects between types of ecological violence and aggressive behavior. Ethnopolitical violence at Wave 1 was associated positively with microsystem violence at Wave 2 even with the inclusion of the significant autoregressive effect of Wave 1 microsystem violence. This effect was present for all three age cohorts. For the youngest age cohort, both microsystem and ethnopolitical violence at Wave 2 predicted increases in aggression from Waves 1 to 3 . For all three age cohorts, we observed significant effects on aggression of ethnopolitical violence at Wave 2 .

Taken together, these observations support two critical developmental theoretical propositions: First, violence in higher levels of the social ecology should beget violence at lower levels of the social ecology. Here, we observed a directional chain of influence from the exosystem to the microsystem to the self-system. Importantly, we were able to set aside a model that included directional effects from Wave 1 aggression to Wave 2 violence exposure. This suggests that despite robust observations of personal-contextual transactions through development (see Sameroff, 2010), with respect to the impact of social-contextual violence, effects seem more likely to be unidirectional from context to person. We also were able to set aside a model that included the reverse of what is implied by Bronfenbrenner's (1979) model - that is, directional effects from proximal violence at Wave 1 to political violence at Wave 2.
Second, younger children should be more susceptible than older children to the effects of witnessed violence. Late childhood (e.g., ages 7-9; Guerra \& Huesmann, 2004; Huesmann, 1998) is a period during which the observation of violence is expected to have especially robust and enduring effects due to its internalization into the child's developing social-cognitive information-processing orientation to the social world. At the same time, our data also support the common point in theorizing that aggression-similar to other behavioralpersonality traits-becomes increasingly stable or continuous with age. Beyond later childhood, contextual factors seem less able to exert significant impact on aggression development-perhaps, of course, because the impact already has occurred. This latter point might be especially relevant under social conditions of chronic violence, in which children might be exposed to violence throughout development. Importantly, though, the observed developmental effects of violence on children's aggression appear to hold primarily for microsystem violence. Our results suggest that ethnopolitical violence is a risk for children with respect to increasing aggressive behavior from late childhood through middle adolescence.

The inclusion of demographic factors into the structural model only somewhat mitigated previously observed effects of contextual violence on aggressive behavior. Effects of parent education and income were significant, but primarily additive, in their influence on aggressive behavior over time. Microsystem violence retained a significant effect on aggression in the youngest cohort. Ethnopolitical violence retained a significant effect on aggression on all three age cohorts. This speaks to the very serious impact of ethnopolitical violence on child adjustment, a finding that has been observed in numerous studies of children exposed to this form of violence in various regions around the world (e.g., Barber, 2008; Kithakye et al., 2010; Quota et al., 2008).

\section{Limitations and Implications}

The present study provides a number of new contributions to the literature but also is marked by a few key limitations. First, our data on exposure to violence were child report or parent report. Although this method is advantageous in that it permits assessment of lived experience, it also can be limiting in its reliance on reporters' recall of events and the biases attendant to such recall. From a theoretical standpoint, self-reports of 
exposure also might not be optimal for indicating aspects of macro- or exosystems as defined by Bronfenbrenner (1979). Future studies should incorporate other indicators of violence exposure, perhaps through the innovative method of supplementing self-reports with historical accounts of violent conflict utilized by Cummings, Schermerhorn, et al. (2010) and Cummings, Merrilees, et al. (2010). As a related point, we note here that we integrated community, family, and school violence as indicators of proximal violence; future work might keep these indicators separate when modeling effects on aggression. Second, as an extension of the first limitation, we recognize that our blending of parent reports of exposure for younger children and self-reports for older children is not optimal, although the reporter appeared not to matter in our data. Future studies should utilize multiple converging sources of information on children's experiences, especially given findings suggesting that parents and children can differ in systematic ways in their reports of children's exposure (Kuo, Mohler, Raudenbush, \& Earls, 2000). Third, given our interest in observational learning, we focused primarily on exposure to violence via witnessing rather than victimization. Victimization by violence appears to exert effects on adjustment via pathways different from witnessing (e.g., Boxer et al., 2008), and future studies could consider the relative effects of both channels of exposure on aggressive behavior. Finally, as reported, we observed meaningful and significant differential attrition across our three study samples. Our sampling methods and very low attrition in the Palestinian sample suggest good representativeness in that group, but our Israeli samples were more problematic and thus limiting. On a related point, we encountered differences in which parents (mothers or fathers) participated in the research (i.e., more fathers reporting in Israel than in Palestine). Although this is not a limitation per se, it does suggest the need for some caution in interpreting results given that it could reflect cultural variation in which parent bears responsibility for the tasks of child rearing, or which parent is more available to take part in home-based research (due, for example, to economic factors).

Despite these limitations, the present study adds to the growing literature base confirming the significant risks for children living under conditions of ethnopolitical conflict and violence (see, e.g., Garbarino, Kostelny, \& Dubrow, 1991; and relevant special issues of Child Development [Vol. 81, 2010; Vol. $67,1996])$ and lends additional urgency to the need for the ongoing field-testing and formal implementation of targeted interventions for children exposed to these events (see Peltonen \& Punamäki, 2010).

\section{References}

Achenbach, T., \& Edelbrock, C. (1983). Manual for the Child Behavior Checklist. Burlington: University of Vermont.

Anderson, C. A., Gentile, D. A., \& Buckley, K. E. (2007). Violent video game effects on children and adolescents. New York: Oxford University Press.

Archer, D., \& Gartner, R. (1984). Violence and crime in cross-national perspective. New Haven, CT: Yale University Press.

Attar, B. K., Guerra, N. G., \& Tolan, P. H. (1994). Neighborhood disadvantage, stressful life events, and adjustment in urban elementary school children. Journal of Clinical Child Psychology, 23, 391-400.

Bandura, A. (1977). Social learning theory. Englewood Cliffs, NJ: Prentice Hall.

Barber, B. K. (1999). Political violence, family relations, and Palestinian youth functioning. Journal of Adolescent Research, 14, 206-230.

Barber, B. K. (2008). Contrasting portraits of war: Youths' varied experiences with political violence in Bosnia and Palestine. International Journal of Behavioral Development, 32, 298-309.

Boxer, P., Guerra, N. G., Huesmann, L. R., \& Morales, J. (2005). Proximal effects of a small-group selected prevention program on aggression in elementary school children: An investigation of the peer contagion hypothesis. Journal of Abnormal Child Psychology, 33, 325-338.

Boxer, P., Gullan, R. L., \& Mahoney, A. (2009). Adolescents' physical aggression towards parents in a clinicreferred sample. Journal of Clinical Child and Adolescent Psychology, 38, 106-116.

Boxer, P., Huesmann, L. R., Bushman, B. J., O'Brien, M., \& Moceri, D. (2009). The role of violent media preferences in cumulative developmental risk for violence and general aggression. Journal of Youth and Adolescence, 38, 417-428.

Boxer, P., Morris, A. S., Terranova, A. M., Kithakye, M., Savoy, S. C., \& McFaul, A. (2008). Coping with exposure to violence: Relations to aggression and emotional symptoms in three urban samples. Journal of Child and Family Studies, 17, 881-893.

Boxer, P., Musher-Eizenman, D. R., Dubow, E. F., Heretick, D. M. L., \& Danner, S. A. (2006). Assessing teachers' perceptions for school-based aggression prevention programs: Applying a cognitive-ecological framework. Psychology in the Schools, 43, 331-344.

Bronfenbrenner, U. (1979). The ecology of human development: Experiments by nature and design. Cambridge, MA: Harvard University Press. 
Bronfenbrenner, U. (2005). Making human beings human: Bioecological perspectives on human development. Thousand Oaks, CA: Sage.

B'Tselem: Israeli Information Center for Human Rights in the Occupied Territories. (2009). Retrieved May 2009, from http://www.btselem.org//english/statistics/ casualties.asp

Cheung, G. W., \& Rensvold, R. B. (2002). Evaluating goodness-of-fit indexes for testing measurement invariance. Structural Equation Modeling, 9, 233-255.

Clark, C. J., Everson-Rose, S. A., Suglia, S. F., Btoush, R., Alonso, A., \& Haj-Yahia, M. M. (2010). Association between exposure to political violence and intimate partner violence in the occupied Palestinian territory: A case-control study. The Lancet, 375, 310-316.

Conger, R. D., Wallace, L. E., Sun, Y., Simons, R. L., McLoyd, V. C., \& Brody, G. H. (2002). Economic pressure in African American families: A replication and extension of the family stress model. Developmental Psychology, 38, 179-193.

Cummings, E. M., \& Davies, P. (1994). Children and marital conflict. New York: Guilford.

Cummings, E. M., Merrilees, C. E., Schermerhorn, A. C., Goecke-Morey, M. C., Shirlow, P., \& Cairns, E. (2010). Testing a social ecological model for relations between political violence and child adjustment in Northern Ireland. Development and Psychopathology, 22, 405-418.

Cummings, E. M., Schermerhorn, A. C., Merrilees, C. E., Goeke-Morey, M. C., Shirlow, P., \& Cairns, E. (2010). Political violence and child adjustment in Northern Ireland: Testing pathways in a social-ecological model including single- and two-parent families. Developmental Psychology, 46, 827-841.

Davis-Kean, P. E., Huesmann, L. R., Jager, J., Collins, W. A., Bates, J. E., \& Lansford, J. (2008). Changes in the relation of self-efficacybeliefs and behaviors across development. Child Development, 79, 1257-1269.

Dodge, K. A., Bates, J. E., \& Pettit, G. S. (1990). Mechanisms in the cycle of violence. Science, 250, 1678-1683.

Dubow, E. F., Boxer, L. R., Huesmann, L. R., Skikaki, K., Landau, S., Gvirsman, S., et al. (2010). Exposure to conflict and violence across contexts: Relations to adjustment among Palestinian children. Journal of Clinical Child and Adolescent Psychology, 39, 103-116.

Eron, L. (1987). The development of aggressive behavior from the perspective of a developing behaviorism. American Psychologist, 42, 435-442.

Eron, L. D., Huesmann, L. R., \& Zelli, A. (1991). The role of parental variables in the learning of aggression. In D. Pepler \& K. Rubin (Eds.), The development and treatment of childhood aggression (pp. 169-188), Hillsdale, NJ: Erlbaum.

Eron, L. D., Walder, L. O., \& Lefkowitz, M. M. (1971). Learning of aggression in children. Boston: Little, Brown.

Espelage, D. L., Holt, M. K., \& Henkel, R. R. (2003). Examination of peer-group contextual effects on aggression during early adolescence. Child Development, 74, 205-220.
Finkelhor, D., Turner, H. A., Ormrod, R. K., \& Hamby, S. L. (2009). Violence, abuse, and crime exposure in a national sample of children and youth. Pediatrics, 124, 1-13.

Garbarino, J., Kostelny, K., \& Dubrow, N. (1991). What children can tell us about living in danger. American Psychologist, 46, 376-383.

Gorman-Smith, D., \& Tolan, P. (1998). The role of exposure to violence in developmental problems among inner-city youth. Development and Psychopathology, 10, 101-116.

Guerra, N. G., \& Huesmann, L. R. (2004). A cognitiveecological model of aggression. International Review of Social Psychology, 17, 177-203.

Guerra, N. G., Huesmann, L. R., \& Spindler, A. (2003). Community violence exposure, social cognition, and aggression among urban elementary school children. Child Development, 74, 1507-1522.

Henry, D., Guerra, N. G., Huesmann, L. R., Tolan, P. H., \& Van Acker, R. (2000). Normative influences on aggression in urban elementary school classrooms. American Journal of Community Psychology, 28, 59-81.

Huesmann, L. R. (1997). Observational learning of violent behavior: Social and biosocial processes. In A. Raine, P. O. Brennen, D. P. Farrington, \& S. A. Mednick (Eds.), The biosocial basis of violence (pp. 69-88). New York: Plenum.

Huesmann, L. R. (1998). The role of social information processing and cognitive schemas in the acquisition and maintenance of habitual aggressive behavior. In R. G. Geen \& E. Donnerstein (Eds.), Human aggression: Theories, research, and implications for policy (pp. 73-109). New York: Academic Press.

Huesmann, L. R., Dubow, E. F., \& Boxer, P. (2009). Continuity of childhood, adolescent, and early adulthood aggression as predictors of adult criminality and life outcomes: Implications for the adolescent-limited and life-course-persistent models. Aggressive Behavior, 35, 136-149.

Huesmann, L. R., \& Kirwil, L. (2007). Why observing violence increases the risk of violent behavior by the observer. In D. J. Flannery, A. T. Vazsonyi \& I. D. Waldman (Eds.), The Cambridge handbook of violent behavior and aggression (pp. 545-570). Cambridge, UK: Cambridge University Press.

Huesmann, L. R., Moise-Titus, J., Podolski, C., \& Eron, L. D. (2003). Longitudinal relations between children's exposure to television violence and their aggressive and violent behavior in young adulthood: 1977-1992. Developmental Psychology, 39, 201-222.

Kithakye, M., Morris, A. S., Terranova, A. M., \& Myers, S. S. (2010). The Kenyan political conflict and children's adjustment. Child Development, 81, 1114-1128.

Kokko, K., Pulkkinen, L., Huesmann, L. R., Dubow, E. F., \& Boxer, P. (2009). Intensity of aggression in childhood as a predictor of different forms of adult aggression: A two-country (Finland and the United States) analysis. Journal of Research on Adolescence, 19, 9-34. 
Krug, E. G., Dahlberg, L. L., Mercy, J. A., Zwi, A. B., \& Lozano, R. (Eds.). (2002). World report on violence and health. Geneva, Switzerland: World Health Organization.

Kuo, M., Mohler, B., Raudenbush, S. L., \& Earls, F. J. (2000). Assessing exposure to violence using multiple informants: Application of hierarchical linear modeling. Journal of Child Psychology and Psychiatry, 41, 1049-1056.

Landau, S. F. (1988). Violent crime and its relation to subjective social stress indicators: The case of Israel. Aggressive Behavior, 14, 337-362.

Landau, S. F. (1997). Homicide in Israel: Its relation to subjective stress and support indicators on the macro level. Homicide Studies, 1, 377-400.

Landau, S. F. (2003). Societal costs of political violence. Palestine-Israel Journal of Politics, Economics, and Culture, 10, 28-35.

Landau, S. F., Gvirsman, S. D., Huesmann, L. R., Dubow, E. F., Boxer, P., Ginges, J., et al. (2010). The effects of exposure to violence on aggressive behavior: The case of Arab and Jewish children in Israel. In K. Österman (Ed.), Indirect and direct aggression (pp. 321-343). Berlin, Germany: Peter Lang.

Landau, S. F., \& Pfeffermann, D. (1988). A time series analysis of violent crime and its relation to prolonged states of warfare: The Israeli case. Criminology, 26, 489504.

Lefkowitz, M. M., Eron, L. D., Walder, L. O., \& Huesmann, L. R. (1977). Growing up to be violent: A longitudinal study of the development of aggression. New York: Pergamon.

Mrug, S., Loosier, P. S., \& Windle, M. (2008). Violence exposure across multiple contexts: Individual and joint effects on adjustment. American Journal of Orthopsychiatry, 78, 70-84.

Palestinian Central Bureau of Statistics (2008, August). Census final results in the West Bank: Summary (Population and Housing). Ramallah, Palestine: Author. Retrieved from http://www.pcbs.gov.ps/Portals/_PCBS/Down loads/book1487.pdf

Nansel, T. R., Overpeck, M., Pilla, R. S., Ruan, W. J., Simons-Morton, B., \& Scheidt, P. (2001). Bullying behaviors among U.S. youth: Prevalence and associa- tion with psychological adjustment. Journal of the American Medical Association, 285, 2094-2100.

Peltonen, K., \& Punamäki, R. (2010). Preventive interventions among children exposed to trauma of armed conflict: A literature review. Aggressive Behavior, 36, 95-116.

Pianta, R. C., Steinberg, M. S., \& Rollins, K. B. (1995). The first two years of school: Teacher-child relationships and deflections in children's classroom adjustment. Development and Psychopathology, 7, 295-312.

Quota, S., Punamäki, R. L., \& El Sarraj, E. (2008). Child development and mental health in war and military violence: The Palestinian experience. International Journal of Behavioral Development, 32, 310-321.

Richards, M. H., Larson, R. W., Miller, B. V., Parrella, D. P., Sims, B., \& McCauley, C. (2004). Risky and protective contexts and exposure to violence in inner city African American adolescents. Journal of Clinical Child and Adolescent Psychology, 33, 145-155.

Rutter, M. (1979). Protective factors in children's responses to stress and disadvantage. In M. W. Kent \& E. J. Rolf (Eds.), Primary prevention of psychopathology, Vol. 3. Social competence in children (pp. 49-74). Hanover, NH: University of New England Press.

Sameroff, A. J. (2000). Dialectical processes in developmental psychopathology. In A. Sameroff, M. Lewis, \& S. Miller (Eds.), Handbook of developmental psychopathology (2nd ed., pp. 23-40). New York: Kluwer Academic/ Plenum.

Sameroff, A. J. (2010). A unified theory of development: A dialectic integration of nature and nurture. Child Development, 81, 6-22.

Slone, M., Lobel, T., \& Gilat, I. (1999). Dimensions of the political environment affecting children's mental health. Journal of Conflict Resolution, 43, 78-91.

Snyder, J., Schrepferman, L., McEachern, A., Barner, S., Provines, J., \& Johnson, K. (2008). Peer deviancy training and peer coercion-rejection: Dual processes associated with early onset conduct problem. Child Development, 79, 252-268.

Tremblay, R. E. (2000). The development of aggressive behaviour during childhood: What have we learned in the past century? International Journal of Behavioral Development, 24, 129-141. 